\title{
The Centennial of a Landmark Case in Obstetric and Gynecologic Law and Ethics: Retelling the Story of Schloendorff vs New York Hospital
}

\author{
1 Judith Chervenak, ${ }^{2}$ Laurence B McCullough, ${ }^{3}$ Frank A Chervenak
}

\begin{abstract}
This paper honors the centennial of a case, Schloendorff vs Society of New York Hospital, that became a landmark in the history of consent for clinical care. For a century, Schloendorff has been understood as a case of surgery done without consent on an anesthetized patient when a pelvic mass was discovered. We honor the centennial of this case by retelling the story of what actually was a case that illustrates the clinical ethical errors that occur when physicians fail to communicate with each other and with their patient. To retell this story, we review the original medical and surgical records, letters of key participants in the case, and the trial-court record. Contrary to what is commonly thought, Ms Schloendorff actually lost her legal case and, indeed, her surgery might not have been performed at all, had her clinicians known, communicated, documented, and reaffirmed what the patient actually wanted. This new perspective on Schloendorff is important for obstetric and gynecologic care, because it vividly documents the perils of the medical errors of implicit consent, delegating the obtaining of consent, and miscommunication among clinicians. In the context of Schloendorff, the modern culture of patient safety and quality that has come to define excellent obstetric and gynecologic care, including ultrasound, should be understood as a powerful preventive to the clinical ethical perils of miscommunication that reduce the quality of patient care and unnecessarily compromise professional obstetric and gynecologic ultrasound.
\end{abstract}

Keywords: Consent, Miscommunication, Patient safety, Schloendorff.

How to cite this article: Chervenak J, McCullough LB, Chervenak FA. The Centennial of a Landmark Case in Obstetric and Gynecologic Law and Ethics: Retelling the Story of Schloendorff vs New York Hospital. Donald School J Ultrasound Obstet Gynecol 2016;10(1):3-8.

Source of support: Nil

Conflict of interest: None

${ }^{1}$ Director, ${ }^{2}$ Professor, ${ }^{3}$ Professor and Chairman

${ }^{1}$ Department of Obstetrics and Gynecology, Bellevue Hospital New York, USA

${ }^{2}$ Center for Medical Ethics and Health Policy, Baylor College of Medicine, Houston, Texas, USA

${ }^{3}$ Department of Obstetrics and Gynecology, Weill Medical College of Cornell University/New York Presbyterian Hospital New York, USA

Corresponding Author: Frank A Chervenak, Professor and Chairman, Department of Obstetrics and Gynecology, New York Presbyterian Hospital, 525 East 68th Street, M-724, Box 122 New York-10065, USA, Phone: 212.746.3012, e-mail: fac2001@ med.cornell.edu

\section{INTRODUCTION}

The John A Burns School of Medicine of the University of Hawai celebrated its 50th anniversary in 2015. The authors would like to honor this anniversary by presenting another important anniversary, in the history of obstetrics and gynecology, law, and ethics, the landmark case, Schloendorff vs Society of New York Hospital, ${ }^{1}$ decided by the highest civil court in the State of New York in 2014. This is one of the most frequently cited legal cases in the obstetric ethics and bioethics literatures for what is taken to be a fundamental contribution to the law and ethics of informed consent. In this paper, we tell a more complicated and more clinically interesting story than the simple story of the invention of simple consent, i.e. the patient's right to say yes or no to recommended clinical management. To do so, we adapt a paper that we previously published on this topic. $^{2}$

The court's opinion in Schloendorff was written by Justice Benjamin Cardozo, who later went on to considerable renown as an Associate Justice of the United States Supreme Court. The standard account in the literature is that surgery was performed on Ms Schloendorff to remove a pelvic mass discovered after she had been anesthetized patient and without her consent. In response, Cardozo wrote: 'Every human being of adult years and sound mind has the right to determine what shall be done with his own body; and a surgeon who performs an operation without his patient's consent, commits an assault, for which he is liable in damages ... except in cases of emergency where the patient is unconscious and where it is necessary to operate before consent can be obtained. ${ }^{1}$ This sentence, a ringing endorsement of patient's rights, appears repeatedly in the informed consent, ${ }^{3}$ biomedical ethics, ${ }^{4}$ and obstetric and gynecologic ethics literature. ${ }^{5,6}$ This sentence is taken to establish the legal basis of consent. Lombardo has recently made an important contribution to how Schloendorff should be understood in the history of common law. Based on a careful scholarly legal analysis of the 1911 trial court record and of Justice Cardozo's 1914 opinion for the Court of Appeals of New York, Lombardo has shown that Schloendorff was not directly about consent but about the immunity from liability of a hospital as a 
charitable organization from the actions of its physicians, surgeons, and nurses. ${ }^{7}$

Our purpose is to explain how Schloendorff should be understood in the history of obstetric and gynecologic ethics and to identify clinically significant implications of this unappreciated for contemporary clinical practice. To this end, we will provide a new, contemporary perspective on Schloendorff that demonstrates its enduring clinical relevance for obstetrics and gynecology. We will show that the Schloendorff case is best interpreted as a warning about the perils of the clinical ethical perils of implicit consent, delegating responsibility for obtaining consent, and the resulting miscommunication among physicians, surgeons, and nurses. Schloendorff should not be considered a landmark case of physician paternalism, in which gynecologic surgery was performed for a patient's benefit but without her express consent, paternalism to which patient autonomy is the remedy. Instead, based on the historical record, Schloendorff is best appreciated as one of the earliest cases that emphasize the clinical perils that result when surgeons fail to communicate effectively with their colleagues and with their patient. These new lessons from Schloendorff have direct application to obstetric ultrasound.

\section{The Untold Story of Schloendorff}

The facts of this landmark care are not well-understood, a problem remedied by retelling the story of the Schloendorff case. To do so, we rely on the trial court record, which is included in the appellate court ruling in this case. ${ }^{8}$ We also rely on the medical ${ }^{9}$ and surgical records, ${ }^{10}$ as well as other contemporaneous primary source materials, ${ }^{11-14}$ in the Medical Center Archives of New York Presbyterian/Weill Cornell Medical Center.

The 56-year-old Ms Schloendorff lost both her uterus and her case and the damages she claimed were the result of an embolism in the brachial artery of her left arm that developed postoperatively. Ms Schloendorff alleged at trial that, while she had given consent for an 'ether examination' to determine if the nature of her pelvic mass, she had explicitly had told the house physicians and nurses that she did not want surgery. Following her unwanted hysterectomy, she sued the hospital and not the surgeons, claiming $\$ 50,000$ in damages for her loss of fingers and her pain and suffering. Ms Schloendorff, through her attorney, alleged that she had an oral contract with the hospital to which she had paid a \$7 per week consideration that she be treated according to her direction and that this had included an explicit instruction not to be operated upon. Interestingly, she did not directly accuse the hospital or its physicians of a battery. It is possible that she did this because her attorney wanted to avoid the hospital's potential defense of charitable immunity, which would have effectively prevented her from suing for the hospital for resulting negligent treatment by the physicians and surgeons. It is also notable that the damages claimed did not include the loss of her fibroid uterus and ovaries as a direct result of the surgery (she was already 56) but rather the significant pain and suffering she underwent as a result of an infection and gangrene in her arm, which developed some weeks later and resulted in the eventual loss of distal parts of some of her fingers.

In 1907 at Society of New York Hospital (SNYH) the medical and surgical services were separate in several dimensions. Today she would be admitted to obstetrics and gynecology for integrated care. Then, there was no defined gynecology service at SNYH. The medical and surgical services were physically separate and had different professional staff. The medical and surgical records at SNYH, which were written in long hand on paper in separately bound volumes, appear to have kept in different places as well. Crucially for the Schloendorff case, there were at least three physicians responsible for her care on the medical service, and then at least three surgeons when she was transferred to the surgery service. There is no documentation in the medical or surgical records that the patient agreed to an ether examination but refused any surgery. There is also no documentation that an ether examination was ever performed, although Ms Schloendorff did admit at trial that that was what she believed she had agreed to and what she was told would happen, at least by Dr Bartlett, the chief physician on the medical service. There is documentation in the medical record indicating that at least one provider, Dr Martin, a house physician under Dr Bartlett (a resident in today's nomenclature), believed that the patient had in fact consented to surgery for what was preoperatively diagnosed as a likely fibroid uterus: 'Wished operation for mass, which is just above the synthesis, size of orange, and rounded. Vaginal examination shows it to be connected to the uterus. ${ }^{\prime 9}$ While the physicians requested and received a surgical consult on their patient, there is conflicting testimony as to what the conclusion and advice given during that consult consisted of beyond the record of an examination in the chart on January 26, 1907, 5 days before she was transferred to the surgery service. There is no documentation of physician-to-surgeon communication during or after the transfer on January 31. These lapses would not be accepted in contemporary clinical practice based on patient and quality, but apparently were acceptable at that time.

At the time of her admission on January 10, 1907, according to the trial court record, the patient was known 
as Mary Gamble, a 56-year-old 'teacher of physical training, voice culture of reduction and development ${ }^{8}$ or voice coach. She had been living in San Francisco at the time of the 1906 earthquake, 9 months earlier, but moved to New York to join her son because she was frightened by this experience during which she lost two sisters. She was admitted initially to the medical service of SNYH, complaining of stomach pain and severe weight loss, which she attributed to anxiety resulting from the earthquake.

During her medical admission she testified in the trial-court proceeding that she was treated conservatively with stomach washings and diet of 'a little bit of raw egg and a little bit of milk and that is all. ${ }^{8}$ The medical record documents that she received different diets, bismuth, gastric lavage, and enemas and gained 11 pounds over the course of her 3-week admission to the medical service. At the end of her medical admission she was declared 'cured of stomach pain' that had been caused by 'acidity.'

Dr Bartlett was her attending hospital physician for her medical admission and his physical examination revealed the incidental finding of an abdominal mass, which she testified that she had been aware of for some time. Dr Bartlett recommended a surgical evaluation of this mass. She was then seen by Dr Stimson, the chief surgeon, and Dr Cottle, a house surgeon (again in today's nomenclature a resident) who was Dr Stimson's assistant. According to her testimony, Dr Stimson was not able to detect the mass because she was 'too nervous, too rigid,' and Dr Stimson said to some other doctors who were on rounds with him that he would have to do an 'ether examination.' ${ }^{8}$ According to her testimony, Dr Stimson did not explain what an ether examination was and Ms Schloendorff testified that she 'did not say anything to him.' ${ }^{8}$ The next time she saw Dr Bartlett she asked him what was meant by an ether examination and told Dr Bartlett explicitly that she did not want an operation. Dr Bartlett assured her that there would be no operation, that the ether examination 'would be very simple' ${ }^{8}$ and would help to determine the nature of the lump. She claimed that Dr Bartlett advised her that she could have surgery at another time. She packed and was ready to leave the next day. Both her landlord and her son testified that Ms Schloendorff had expected to be discharged in a few days, the landlord even producing a letter which was used as evidence of the patient's intention.

Dr Stimson testified that he saw Ms Gamble on the medical service on January 26. He testified that he was able to perform a physical examination with one hand on her abdomen and the fingers of his other hand 'in the lower bowel and vagina and got it between the two hands. ${ }^{8}$ He testified that his diagnosis was a 'multiple fibroid tumor. ${ }^{8}$ He also testified that there was no need for an ether examination; his diagnosis had precluded the need for such an examination. An unsigned note in the medical record dated January 26th would support this testimony. Dr Stimson claimed that he said to Ms Gamble that he would perform surgery 'if she wanted it removed.' He added: 'she did not say she was opposed to an operation. ${ }^{8}$ Dr Bartlett, whose deposition testimony was introduced at trial, claimed that Ms Schloendorff 'expressed a desire to have an operation' ${ }^{8}$ and that is why he requested the consult from Dr Stimson and his staff. Dr Bartlett did not recall her ever objecting to surgery.

There is an entry in the medical record for January 31 , as noted above, that states that the patient 'wishes operation. ${ }^{\prime 9}$ This entry was signed by 'Art Martin HD.' Dr Arthur H Martin's formal title was Second Senior Assistant (HD or House Doctor) on the medical service under Dr Bartlett. Dr Martin did not testify at the trial and his name appears nowhere in the other primary source materials documents that we examined.

According to Ms Schloendorff's testimony, she was awoken by a nurse the evening of January 31 and informed that she was to go the 'next ward, ${ }^{8}$ i.e. the separate surgery service. She asked if this would interfere with her going home and was told that she would have an ether examination in the morning, without a meal beforehand. At some point she was shaved and her body washed and covered with antiseptic cloths. She claims that she questioned whether this preparation was necessary for an ether examination and, after being told that it was, reiterated again to the nurse that she did not want an operation. An order for preoperative preparation appears in the surgical record. According to Dr Stimson, such preparation would not have been necessary for an ether examination alone. Ms Schloendorff claimed that she was shown a slip on the wall with her name and the words ether examination. Nurse Montague, who prepared her, testified that she did not have a conversation with the patient about the surgery and Nurse Oliver, who brought her to the room where the ether was administered, testified that no such 'cards' ${ }^{8}$ or slips were used in the hospital.

Ms Schloendorff testified that she was taken by elevator in the surgical ward to another room where she was informed by the attendant that she would receive gas followed by ether. She told him that she did want an operation and the attendant assured her that, while he did not know what she was to have, she should not worry. She asked to see somebody about the operation but nobody came. She tried to leave but was restrained by hand. The mouthpiece was placed in her mouth and she was instructed to breathe deeply and lost consciousness. 
She awoke to discover that she had indeed had surgery. The operative note would seem to support the hospital's version of events as there is no mention of any ether examination done prior to surgery. However, it is conceivable that an examination under anesthesia may have been done as a routine prior to any laparotomy.

Ms Schloendorff testified that she did not see Dr Stimson or speak to him before the operation and that after the operation she saw him only once. She asked Dr Cottle, Dr Stimson's assistant, several times what had happened and he was nonresponsive. She asked to talk with Dr Stimson and was told he had left the hospital and was away from the city. She noticed one morning that the fingers of her left hand were blue in some places and black in others. She asked Dr Cottle to look at her hand, which he did, but she claimed that he did nothing. This complication resulted eventually in surgical removal of the tips of her left thumb and forefinger at another hospital. This injury, and not the lack of consent and not the loss of her uterus, prompted her to file a negligence claim against the $\mathrm{SNYH}$.

At trial, the testimony of the doctors and nurses involved in her care provided a much different account of events. The nurses did not recall that Ms Schloendorff had notified them that she did not want surgery, that she protested, or that she had ever complained of having surgery against her wishes following the operation.

As at that time there was neither the custom nor the requirement, as there is now, to obtain written consent, there was a distinct issue of fact, whether Ms Schloendorff had consented or not, which could have been decided by the jury. What prevented a jury from deliberating was that Ms Schloendorff did not sue her doctors at SNYH for trespass or battery, but the hospital itself, alleging that it, through its agents, the physicians and nurses, violated an oral contract by not following her expressed desire not to have an operation. It was determined that there was no legal contract and that the hospital was immune as a charitable organization from the negligent actions of its physicians, and surgeons, as long as the physicians and surgeons were appropriately appointed and hired. The trial court Judge, therefore, directed a verdict in the hospital's favor and the trial and its testimony became moot.

On March 10, 1911, 2 months before the trial, Mr Wilson M Powell, SNYH's outside counsel, wrote to the SNYH Committee on Law that the plaintiff was willing to settle for $\$ 1500$ rather than the $\$ 50000$ originally sought. ${ }^{11}$ In a March 14, 1911, letter from Mr Gerry, the Chairman of the Committee on Law, to Powell, Gerry states that SNYH will not settle, to avoid setting 'precedent which any such course might establish in like cases in the future. ${ }^{\prime 12}$ In a March 23, 1911 letter from the Committee on Law to Mr George Rives, the president of SNYH, the Committee states that not settling was 'fully in accord with the uniform rule which the Hospital has adopted for many years. ${ }^{13}$ A July 19, 1911, report from Powell to Mr Edward W Sheldon, Superintendant of $\mathrm{SNYH}$, indicates that this rule dated from at least $1877 .{ }^{14}$ The leadership of SNYH was not prepared to do anything that would jeopardize the immunity of the Hospital as a charitable organization from liability for the conduct of its physicians, surgeons, and nurses in the care of the Hospital's patients.

As Ms Schloendorff's case was never sent to the jury, which is the fact finder in US courts, the factual issue of whether she had actually given consent was never determined at trial nor by Justice Cardozo, whose decision on the law for New York's highest court in favor of the hospital upheld the trial court's order of a directed verdict. Cardozo, finding that the physicians were independent contractors and that the nurses were required to follow the orders of physicians and surgeons, agreed with the lower court judge's ruling that the hospital was immune from any damages as a result of the alleged negligence or potential battery of the physicians, surgeons and other hospital personnel. He cited the case as unique since its outcome did not rely upon the implied waiver of charitable immunity which would have been a valid defense against negligent treatment. He argued that the immunity extended to hospitals because its physicians operated independently and were not in its direct control, which also shielded the hospital from responsibility for any potential battery if Ms Schloendorff's testimony was to be believed.

Rather than emerge victorious as the result of her case, Ms Schloendorff was ordered to pay the costs of her trial and the appeal (\$292.62 and \$79, respectively). Lombardo is correct that the legal result of Schloendorff was to uphold the charitable immunity for hospitals in New York State, based on the relationship between a hospital and its physicians and surgeons. Cardozo's ringing endorsement of self-determination, while certainly eloquent, was merely a reiteration of what both the doctors and trial courts before him believed was appropriate in nonemergent cases with a patient capable of understanding and giving consent.

Our retelling of the Schloendorff story corrects three potential misunderstandings of it. First, the plaintiff, Ms Schloendorff, did not bring action to compensate her for the loss of her uterus. Instead, she brought action to compensate her for anatomical and functional losses in her left hand that, she alleged, were the result of a rare complication, a brachial embolism. However, that 
complication may not have been related to her surgery or, if so related, was perhaps an acceptable complication and not the result of negligence. Second, that she brought action against SNYH opened the possibility of a directed verdict in the trial court, which indeed occurred and resulted in the facts of the case never being adjudicated. Third, Schloendorff has been widely cited in the informed consent ${ }^{3}$ and biomedical ethics ${ }^{4}$ literature for at least the past three decades as a landmark case that established the right of a competent adult patient to consent. Schloendorff has achieved this status on the assumption that Mary Gamble, later Mary Schloendorff, was subjected to surgery over her objection. Our retelling of the Schloendorff story, based on the historical materials that we have presented, calls this assumption into question. What is clear is that we, like the surgeons at the time, are still not sure of what Ms Schloendorff really wanted and what she was told prior to her surgery and before experiencing its aftermath.

\section{Clinical Implications}

The enduring historical lesson of Schloendorff for modern obstetrics and gynecology lies elsewhere: the clinical perils of the medical ethical errors of implicit consent and delegating the obtaining of consent that resulted in miscommunication. Mary Gamble was admitted first to the medical service of SNYH, where she received treatment for her chief complaint of abdominal pain, which was declared cured at the end of her medical admission on January 31, 1907. During her medical admission, a mass was found incidentally and a surgical consult was obtained and its results documented on January 26. Surgery was recommended, which the patient neither accepted nor refused at the time. However, on January 31, the last day of her medical admission, there is an entry from Dr Martin that documents what appears to be at least implicit consent to surgical removal of her uterine fibroid tumor and no mention of a diagnostic or preliminary ether examination. There is no documentation of communication of this implicit consent to the surgical service nor of any limitations. The absence of any notation in the surgical record of the patient's consent is puzzling and leaves unclear what that service understood they were asked and had been given permission to do. Therefore, the oft-cited ether examination should be considered apocryphal.

There were two failures of consent. The first was that the patient's implicit, rather than explicit, consent to surgery appears to have been obtained during her medical admission. Second, the hierarchical structure of hospitals at the time, with the chief physician or surgeon at the top and house physicians and house surgeons at the bottom, appears to have resulted in delegation of responsibility for the consent to surgery to the most junior house physician, Dr Martin.

These two failures regarding consent resulted from failures of communication. There is no evidence that the physicians communicated to the surgeons that the patient had consented to surgery. This failure was enabled by the absence of a written consent form and documentation of her consent only in the medical record, which was not physically available to the surgeons. Reliance on what appears to have been implicit consent and the absence of documentation of Ms Gamble's alleged refusal led to surgery that the patient later said that she never authorized. There were also house doctors on the medical service and on the surgery service house surgeons, an anesthesiologist, and nurses who were in a position to question the validity of her consent, either affirming it or bringing any limitations to the surgeon's notice. There was at the time apparently no formal mechanism for them to stop the chain of events.

In today's culture of patient safety and quality, it is not permissible to delegate the consent process to a clinician not qualified by training and experience, as was Dr Martin, to lead and document the informed consent process. This is as true of obstetric ultrasound examination as it is for other clinical management. There is no requirement for written documentation of consent to obstetric or gynecologic ultrasound, but there is an ethical requirement for adequate prenatal informed consent for sonogram (PICS), ${ }^{15}$ an important preventive ethics component of professional obstetric care.

In addition, upon receiving a patient for surgery or an invasive procedure a time out is routinely called. The documentation of the consent process in progress notes and a signed operative permit would be confirmed. This includes assurance that the appropriately trained and experienced clinician led the consent process, which did not happen in the Schloendorff case. We emphasize that the requirement of a signed operative permit is ethically very significant, not just because it formalizes the patient's consent but also communicates that consent to everyone on the care team. Implicit consent and its perils of miscommunication are thereby prevented. Had such a formal, institutionally required mechanism existed in 1907 at SNYH, miscommunication would almost certainly have been prevented as Ms Gamble was transferred from the medical to the surgical service and when she was taken to the operating room. Now, the patient would be asked why she was there and, if she objected to surgery, her objection would be addressed before any procedure would be done. By contrast, according to her testimony, Ms Gamble's refusal of surgery was ignored when she 
arrived on the surgery service. These practices reflect the enduring legacy of Schloendorff and Cardozo's memorable language: implicit consent is not acceptable; only explicit consent or refusal is, to prevent a cascade of miscommunication.

\section{CONCLUSION}

It is commonly assumed that Ms Schloendorff was the victim of an intentional battery but in truth she may have been victimized by a lack of communication among clinicians who would have ethically and legally respected her wishes not to have surgery, if indeed that had been her express decision. It is also possible that the physicians, surgeons, and SNYH have become the victims of a century of a misunderstanding in a case which they won on the grounds of a directed verdict and the immunity for hospitals that was prevalent at the time. The widely held belief that Ms Schloendorff did not consent was never adjudicated to be a matter of fact.

When carefully examined in its historical and clinical context, Schloendorff vs Society of New York Hospital is better understood as a landmark case for preventable clinical ethical errors of miscommunication. In the context of Schloendorff, the modern culture of patient safety and quality that has come to define excellent obstetric and gynecologic care, including ultrasound, should be understood as a powerful preventive to the clinical ethical perils of miscommunication that reduce the quality of patient care and unnecessarily compromise professional obstetric and gynecologic ultrasound.

\section{REFERENCES}

1. Schloendorff v. Society of New York Hospital, 211 NY 125, 1914;129-130.
2. Chervenak J, McCullough LB, Chervenak FA. Surgery without consent or miscommunication? a new look at a landmark legal case. Am J Obstet Gynecol 2015;212:586-590.

3. Faden RR, Beauchamp TL. A History and Theory of Informed Consent. New York: Oxford University Press; 1986.

4. Beauchamp TL, Childress JF. Principles of Biomedical Ethics. 7th ed. New York: Oxford University Press; 2013.

5. Chervenak FA, McCullough LB. Preventive ethics for cesarean delivery: the time has come. Am J Obstet Gynecol 2013 Sep;209(3):166-167.

6. Chervenak FA, McCullough LB, Brent RL. The perils of the imperfect expectation of the perfect baby. Am J Obstet Gynecol 2010 Aug;203(2):101.e1-5.

7. Lombardo PA. Phantom tumors and hysterical women: revising our view of the Schloendorff case. J Law Med Ethics 2005;33:791-801.

8. Court of Appeals, State of New York, Briefs and Records, Mary E Schloendorff against The Society of New York Hospital 1914.

9. Ward L, History No. 14789, New York Hospital, for Mary C Gamble, January 10 through January 31, 1907. Medical Center Archives of New York Presbyterian/Weill Cornell Medical Center.

10. Ward M, History No. 32886, New York Hospital, for Mary C Gamble, January 31 through April 19, 1907. Medical Center Archives of New York Presbyterian/Weill Cornell MedicalCenter.

11. Letter of Wilson M Powell to Society of New York Hospital Committee on Law. March 10, 1911. Medical Center Archives of New York Presbyterian/Weill Cornell Medical Center.

12. Letter from Society of New York Hospital Committee on Law to Wilson M Powell. March 14, 1911. Medical Center Archives of New York Presbyterian/Weill Cornell Medical Center.

13. Letter from Society of New York Hospital Committee on Law to George Rives, President of Society of New York Hospital. March 23, 1911. Medical Center Archives of New York Presbyterian/Weill Cornell Medical Center.

14. Letter from Wilson M Powell to Edward W. Sheldon, Superintendant of Society of New York Hospital. July 19, 1911. Medical Center Archives of New York Presbyterian/ Weill Cornell Medical Center.

15. Chervenak FA, McCullough LB, Chervenak JL. Prenatal informed consent for sonogram: an indication for obstetric ultrasonography. Am J Obstet Gynecol 1989;161:857-860. 